\title{
A new generalization of the Banach contraction principle
}

\author{
Mohamed Jleli and Bessem Samet ${ }^{*}$
}

${ }^{\text {"Correspondence: }}$

bsamet@ksu.edu.sa

Department of Mathematics,

College of Science, King Saud

University, P.O. Box 2455, Riyadh,

11451, Saudi Arabia

\begin{abstract}
We present a new generalization of the Banach contraction principle in the setting of Branciari metric spaces.
\end{abstract}

Keywords: Banach contraction; generalized metric; fixed point

\section{Introduction}

The fixed-point theorem, generally known as the Banach contraction principle, appeared in explicit form in Banach's thesis in 1922 [1], where it was used to establish the existence of a solution to an integral equation. Since then, because of its simplicity and usefulness, it has become a very popular tool in solving existence problems in many branches of mathematical analysis. This principle states that, if $(X, d)$ is a complete metric space and $T: X \rightarrow X$ is a contraction map (i.e., $d(T x, T y) \leq \lambda d(x, y)$ for all $x, y \in X$, where $\lambda \in(0,1)$ is a constant), then $T$ has a unique fixed point.

The Banach contraction principle has been generalized in many ways over the years. In some generalizations, the contractive nature of the map is weakened; see [2-9] and others. In other generalizations, the topology is weakened; see [10-23] and others. In [24], Nadler extended the Banach fixed-point theorem from single-valued maps to set-valued contractive maps. Other fixed point results for set-valued maps can be found in [25-30] and references therein.

In 2000, Branciari [11] introduced the concept of generalized metric spaces, where the triangle inequality is replaced by the inequality $d(x, y) \leq d(x, u)+d(u, v)+d(v, y)$ for all pairwise distinct points $x, y, u, v \in X$. Various fixed point results were established on such spaces; see $[10,13,17-20,22]$ and references therein.

In this paper, we introduce a new type of contractive maps and we establish a new fixedpoint theorem for such maps on the setting of generalized metric spaces.

\section{Main results}

We denote by $\Theta$ the set of functions $\theta:(0, \infty) \rightarrow(1, \infty)$ satisfying the following conditions:

$\left(\Theta_{1}\right) \theta$ is non-decreasing;

$\left(\Theta_{2}\right)$ for each sequence $\left\{t_{n}\right\} \subset(0, \infty), \lim _{n \rightarrow \infty} \theta\left(t_{n}\right)=1$ if and only if $\lim _{n \rightarrow \infty} t_{n}=0^{+}$;

$\left(\Theta_{3}\right)$ there exist $r \in(0,1)$ and $\ell \in(0, \infty]$ such that $\lim _{t \rightarrow 0^{+}} \frac{\theta(t)-1}{t^{r}}=\ell$.

Before we prove the main results, we recall the following definitions introduced in [11]. 
Definition 2.1 Let $X$ be a non-empty set and $d: X \times X \rightarrow[0, \infty)$ be a mapping such that for all $x, y \in X$ and for all distinct points $u, v \in X$, each of them different from $x$ and $y$, one has

(i) $d(x, y)=0 \Longleftrightarrow x=y$;

(ii) $d(x, y)=d(y, x)$;

(iii) $d(x, y) \leq d(x, u)+d(u, v)+d(v, y)$.

Then $(X, d)$ is called a generalized metric space (or for short g.m.s.).

Definition 2.2 Let $(X, d)$ be a g.m.s., $\left\{x_{n}\right\}$ be a sequence in $X$ and $x \in X$. We say that $\left\{x_{n}\right\}$ is convergent to $x$ if and only if $d\left(x_{n}, x\right) \rightarrow 0$ as $n \rightarrow \infty$. We denote this by $x_{n} \rightarrow x$.

Definition 2.3 Let $(X, d)$ be a g.m.s. and $\left\{x_{n}\right\}$ be a sequence in $X$. We say that $\left\{x_{n}\right\}$ is Cauchy if and only if $d\left(x_{n}, x_{m}\right) \rightarrow 0$ as $n, m \rightarrow \infty$.

Definition 2.4 Let $(X, d)$ be a g.m.s. We say that $(X, d)$ is complete if and only if every Cauchy sequence in $X$ converges to some element in $X$.

The following result was established in [31] (Lemma 1.10).

Lemma 2.1 Let $(X, d)$ be a g.m.s., $\left\{x_{n}\right\}$ be a Cauchy sequence in $(X, d)$, and $x, y \in X$. Suppose that there exists a positive integer $N$ such that

(i) $x_{n} \neq x_{m}$, for all $n, m>N$;

(ii) $x_{n}$ and $x$ are distinct points in $X$, for all $n>N$;

(iii) $x_{n}$ and $y$ are distinct points in $X$, for all $n>N$;

(iv) $\lim _{n \rightarrow \infty} d\left(x_{n}, x\right)=\lim _{n \rightarrow \infty} d\left(x_{n}, y\right)$.

Then we have $x=y$.

We observe easily that if one of the conditions (ii) or (iii) is not satisfied, then the result of Lemma 2.1 is still valid.

Now, we are ready to state and prove our main result.

Theorem 2.1 Let $(X, d)$ be a complete g.m.s. and $T: X \rightarrow X$ be a given map. Suppose that there exist $\theta \in \Theta$ and $k \in(0,1)$ such that

$$
x, y \in X, \quad d(T x, T y) \neq 0 \quad \Longrightarrow \quad \theta(d(T x, T y)) \leq[\theta(d(x, y))]^{k} .
$$

Then T has a unique fixed point.

Proof Let $x \in X$ be an arbitrary point in $X$. If for some $p \in \mathbb{N}$, we have $T^{p} x=T^{p+1} x$, then $T^{p} x$ will be a fixed point of $T$. So, without restriction of the generality, we can suppose that $d\left(T^{n} x, T^{n+1} x\right)>0$ for all $n \in \mathbb{N}$. Now, from (1), for all $n \in \mathbb{N}$, we have

$$
\begin{aligned}
\theta\left(d\left(T^{n} x, T^{n+1} x\right)\right) & \leq\left[\theta\left(d\left(T^{n-1} x, T^{n} x\right)\right)\right]^{k} \leq\left[\theta\left(d\left(T^{n-2} x, T^{n-1} x\right)\right)\right]^{k^{2}} \\
& \leq \cdots \leq[\theta(d(x, T x))]^{k^{n}} .
\end{aligned}
$$

Thus, we have

$$
1 \leq \theta\left(d\left(T^{n} x, T^{n+1} x\right)\right) \leq[\theta(d(x, T x))]^{k^{n}}, \quad \text { for all } n \in \mathbb{N} .
$$


Letting $n \rightarrow \infty$ in (2), we obtain

$$
\theta\left(d\left(T^{n} x, T^{n+1} x\right)\right) \rightarrow 1 \quad \text { as } n \rightarrow \infty,
$$

which implies from $\left(\Theta_{2}\right)$ that

$$
\lim _{n \rightarrow \infty} d\left(T^{n} x, T^{n+1} x\right)=0
$$

From condition $\left(\Theta_{3}\right)$, there exist $r \in(0,1)$ and $\ell \in(0, \infty]$ such that

$$
\lim _{n \rightarrow \infty} \frac{\theta\left(d\left(T^{n} x, T^{n+1} x\right)\right)-1}{\left[d\left(T^{n} x, T^{n+1} x\right)\right]^{r}}=\ell .
$$

Suppose that $\ell<\infty$. In this case, let $B=\ell / 2>0$. From the definition of the limit, there exists $n_{0} \in \mathbb{N}$ such that

$$
\left|\frac{\theta\left(d\left(T^{n} x, T^{n+1} x\right)\right)-1}{\left[d\left(T^{n} x, T^{n+1} x\right)\right]^{r}}-\ell\right| \leq B, \quad \text { for all } n \geq n_{0} .
$$

This implies that

$$
\frac{\theta\left(d\left(T^{n} x, T^{n+1} x\right)\right)-1}{\left[d\left(T^{n} x, T^{n+1} x\right)\right]^{r}} \geq \ell-B=B, \quad \text { for all } n \geq n_{0} .
$$

Then

$$
n\left[d\left(T^{n} x, T^{n+1} x\right)\right]^{r} \leq A n\left[\theta\left(d\left(T^{n} x, T^{n+1} x\right)\right)-1\right], \quad \text { for all } n \geq n_{0},
$$

where $A=1 / B$.

Suppose now that $\ell=\infty$. Let $B>0$ be an arbitrary positive number. From the definition of the limit, there exists $n_{0} \in \mathbb{N}$ such that

$$
\frac{\theta\left(d\left(T^{n} x, T^{n+1} x\right)\right)-1}{\left[d\left(T^{n} x, T^{n+1} x\right)\right]^{r}} \geq B, \quad \text { for all } n \geq n_{0} .
$$

This implies that

$$
n\left[d\left(T^{n} x, T^{n+1} x\right)\right]^{r} \leq A n\left[\theta\left(d\left(T^{n} x, T^{n+1} x\right)\right)-1\right], \quad \text { for all } n \geq n_{0},
$$

where $A=1 / B$.

Thus, in all cases, there exist $A>0$ and $n_{0} \in \mathbb{N}$ such that

$$
n\left[d\left(T^{n} x, T^{n+1} x\right)\right]^{r} \leq A n\left[\theta\left(d\left(T^{n} x, T^{n+1} x\right)\right)-1\right], \quad \text { for all } n \geq n_{0}
$$

Using (2), we obtain

$$
n\left[d\left(T^{n} x, T^{n+1} x\right)\right]^{r} \leq A n\left([\theta(d(x, T x))]^{k^{n}}-1\right), \quad \text { for all } n \geq n_{0} .
$$


Letting $n \rightarrow \infty$ in the above inequality, we obtain

$$
\lim _{n \rightarrow \infty} n\left[d\left(T^{n} x, T^{n+1} x\right)\right]^{r}=0 .
$$

Thus, there exists $n_{1} \in \mathbb{N}$ such that

$$
d\left(T^{n} x, T^{n+1} x\right) \leq \frac{1}{n^{1 / r}}, \quad \text { for all } n \geq n_{1} .
$$

Now, we shall prove that $T$ has a periodic point. Suppose that it is not the case, then $T^{n} x \neq T^{m} x$ for every $n, m \in \mathbb{N}$ such that $n \neq m$. Using (1), we obtain

$$
\begin{aligned}
\theta\left(d\left(T^{n} x, T^{n+2} x\right)\right) & \leq\left[\theta\left(d\left(T^{n-1} x, T^{n+1} x\right)\right)\right]^{k} \leq\left[\theta\left(d\left(T^{n-2} x, T^{n} x\right)\right)\right]^{k^{2}} \\
& \leq \cdots \leq\left[\theta\left(d\left(x, T^{2} x\right)\right)\right]^{k^{n}} .
\end{aligned}
$$

Letting $n \rightarrow \infty$ in the above inequality and using $\left(\Theta_{2}\right)$, we obtain

$$
\lim _{n \rightarrow \infty} d\left(T^{n} x, T^{n+2} x\right)=0
$$

Similarly, from condition $\left(\Theta_{3}\right)$, there exists $n_{2} \in \mathbb{N}$ such that

$$
d\left(T^{n} x, T^{n+2} x\right) \leq \frac{1}{n^{1 / r}}, \quad \text { for all } n \geq n_{2} .
$$

Let $N=\max \left\{n_{0}, n_{1}\right\}$. We consider two cases.

Case 1. If $m>2$ is odd, then writing $m=2 L+1, L \geq 1$, using (4), for all $n \geq N$, we obtain

$$
\begin{aligned}
d\left(T^{n} x, T^{n+m} x\right) & \leq d\left(T^{n} x, T^{n+1} x\right)+d\left(T^{n+1} x, T^{n+2} x\right)+\cdots+d\left(T^{n+2 L} x, T^{n+2 L+1} x\right) \\
& \leq \frac{1}{n^{1 / r}}+\frac{1}{(n+1)^{1 / r}}+\cdots+\frac{1}{(n+2 L)^{1 / r}} \\
& \leq \sum_{i=n}^{\infty} \frac{1}{i^{1 / r}} .
\end{aligned}
$$

Case 2. If $m>2$ is even, then writing $m=2 L, L \geq 2$, using (4) and (6), for all $n \geq N$, we obtain

$$
\begin{aligned}
d\left(T^{n} x, T^{n+m} x\right) & \leq d\left(T^{n} x, T^{n+2} x\right)+d\left(T^{n+2} x, T^{n+3} x\right)+\cdots+d\left(T^{n+2 L-1} x, T^{n+2 L} x\right) \\
& \leq \frac{1}{n^{1 / r}}+\frac{1}{(n+2)^{1 / r}}+\cdots+\frac{1}{(n+2 L-1)^{1 / r}} \\
& \leq \sum_{i=n}^{\infty} \frac{1}{i^{1 / r}} .
\end{aligned}
$$

Thus, combining all the cases we have

$$
d\left(T^{n} x, T^{n+m} x\right) \leq \sum_{i=n}^{\infty} \frac{1}{i^{1 / r}}, \quad \text { for all } n \geq N, m \in \mathbb{N}
$$


From the convergence of the series $\sum_{i} \frac{1}{i^{1 / r}}($ since $1 / r>1)$, we deduce that $\left\{T^{n} x\right\}$ is a Cauchy sequence. Since $(X, d)$ is complete, there is $z \in X$ such that $T^{n} x \rightarrow z$. On the other hand, observe that $T$ is continuous, indeed, if $T x \neq T y$, then we have from (1)

$$
\ln [\theta(d(T x, T y))] \leq k \ln [\theta(d(x, y))] \leq \ln [\theta(d(x, y))]
$$

which implies from $\left(\Theta_{1}\right)$ that

$$
d(T x, T y) \leq d(x, y), \quad \text { for all } x, y \in X
$$

From this observation, for all $n \in \mathbb{N}$, we have

$$
d\left(T^{n+1} x, T z\right) \leq d\left(T^{n} x, z\right)
$$

Letting $n \rightarrow \infty$ in the above inequality, we get $T^{n+1} x \rightarrow T z$. From Lemma 2.1, we obtain $z=T z$, which is a contradiction with the assumption: $T$ does not have a periodic point. Thus $T$ has a periodic point, say $z$, of period $q$. Suppose that the set of fixed points of $T$ is empty. Then we have

$$
q>1 \text { and } d(z, T z)>0 .
$$

Using (1), we obtain

$$
\theta(d(z, T z))=\theta\left(d\left(T^{n} z, T^{n+1} z\right)\right) \leq[\theta(d(z, T z))]^{k^{n}}<\theta(d(z, T z))
$$

which is a contradiction. Thus, the set of fixed points of $T$ is non-empty, that is, $T$ has at least one fixed point. Now, suppose that $z, u \in X$ are two fixed points of $T$ such that $d(z, u)=d(T z, T u)>0$. Using $(1)$, we obtain

$$
\theta(d(z, u))=\theta(d(T z, T u)) \leq[\theta(d(z, u))]^{k}<\theta(d(z, u))
$$

which is a contradiction. Then we have one and only one fixed point.

Since a metric space is a g.m.s., from Theorem 2.1, we deduce immediately the following result.

Corollary 2.1 Let $(X, d)$ be a complete metric space and $T: X \rightarrow X$ be a given map. Suppose that there exist $\theta \in \Theta$ and $k \in(0,1)$ such that

$$
x, y \in X, \quad d(T x, T y) \neq 0 \quad \Longrightarrow \quad \theta(d(T x, T y)) \leq[\theta(d(x, y))]^{k}
$$

Then T has a unique fixed point.

Observe that the Banach contraction principle follows immediately from Corollary 2.1. Indeed, if $T$ is a Banach contraction, i.e., there exists $\lambda \in(0,1)$ such that

$$
d(T x, T y) \leq \lambda d(x, y), \quad \text { for all } x, y \in X
$$


then we have

$$
e^{d(T x, T y)} \leq\left[e^{d(x, y)}\right]^{k}, \quad \text { for all } x, y \in X .
$$

Clearly the function $\theta:(0, \infty) \rightarrow(1, \infty)$ defined by $\theta(t):=e^{\sqrt{t}}$ belongs to $\Theta$. So, the existence and uniqueness of the fixed point follows from Corollary 2.1. In the following example (inspired by [9]), we show that Corollary 2.1 is a real generalization of the Banach contraction principle.

Example Let $X$ be the set defined by

$$
X:=\left\{\tau_{n}: n \in \mathbb{N}\right\},
$$

where

$$
\tau_{n}:=\frac{n(n+1)}{2}, \quad \text { for all } n \in \mathbb{N} \text {. }
$$

We endow $X$ with the metric $d$ given by $d(x, y):=|x-y|$ for all $x, y \in X$. It is not difficult to show that $(X, d)$ is a complete metric space. Let $T: X \rightarrow X$ be the map defined by

$$
T \tau_{1}=\tau_{1}, \quad T \tau_{n}=\tau_{n-1}, \quad \text { for all } n \geq 2 .
$$

Clearly, the Banach contraction is not satisfied. In fact, we can check easily that

$$
\lim _{n \rightarrow \infty} \frac{d\left(T \tau_{n}, T \tau_{1}\right)}{d\left(\tau_{n}, \tau_{1}\right)}=1
$$

Now, consider the function $\theta:(0, \infty) \rightarrow(1, \infty)$ defined by

$$
\theta(t):=e^{\sqrt{t e^{t}}}
$$

It is not difficult to show that $\theta \in \Theta$. We shall prove that $T$ satisfies the condition (1), that is,

$$
d\left(T \tau_{n}, T \tau_{m}\right) \neq 0 \quad \Longrightarrow \quad e^{\sqrt{d\left(T \tau_{n}, T \tau_{m}\right) e^{d\left(T \tau_{n}, T \tau_{m}\right)}}} \leq e^{k \sqrt{d\left(\tau_{n}, \tau_{m}\right) e^{d\left(\tau_{n}, \tau_{m}\right)}}},
$$

for some $k \in(0,1)$. The above condition is equivalent to

$$
d\left(T \tau_{n}, T \tau_{m}\right) \neq 0 \quad \Longrightarrow \quad d\left(T \tau_{n}, T \tau_{m}\right) e^{d\left(T \tau_{n}, T \tau_{m}\right)} \leq k^{2} d\left(\tau_{n}, \tau_{m}\right) e^{d\left(\tau_{n}, \tau_{m}\right)}
$$

So, we have to check that

$$
d\left(T \tau_{n}, T \tau_{m}\right) \neq 0 \quad \Longrightarrow \quad \frac{d\left(T \tau_{n}, T \tau_{m}\right) e^{d\left(T \tau_{n}, T \tau_{m}\right)-d\left(\tau_{n}, \tau_{m}\right)}}{d\left(\tau_{n}, \tau_{m}\right)} \leq k^{2}
$$

for some $k \in(0,1)$. We consider two cases. 
Case $1 . n=1$ and $m>2$. In this case, we have

$$
\begin{aligned}
& \frac{d\left(T \tau_{1}, T \tau_{m}\right) e^{d\left(T \tau_{1}, T \tau_{m}\right)-d\left(\tau_{1}, \tau_{m}\right)}}{d\left(\tau_{1}, \tau_{m}\right)} \\
& =\frac{m^{2}-m-2}{m^{2}+m-2} e^{-m} \\
& \leq e^{-1} .
\end{aligned}
$$

Case 2. $m>n>1$. In this case, we have

$$
\begin{aligned}
& \frac{d\left(T \tau_{m}, T \tau_{n}\right) e^{d\left(T \tau_{m}, T \tau_{n}\right)-d\left(\tau_{m}, \tau_{n}\right)}}{d\left(\tau_{m}, \tau_{n}\right)} \\
& =\frac{m+n-1}{m+n+1} e^{n-m} \\
& \leq e^{-1}
\end{aligned}
$$

Thus, the inequality (7) is satisfied with $k=e^{-1 / 2}$. Theorem 2.1 (or Corollary 2.1) implies that $T$ has a unique fixed point. In this example $\tau_{1}$ is the unique fixed point of $T$.

Note that $\Theta$ contains a large class of functions. For example, for

$$
\theta(t):=2-\frac{2}{\pi} \arctan \left(\frac{1}{t^{\alpha}}\right), \quad 0<\alpha<1, t>0,
$$

we obtain from Theorem 2.1 the following result.

Corollary 2.2 Let $(X, d)$ be a complete g.m.s. and $T: X \rightarrow X$ be a given map. Suppose that there exist $\alpha, k \in(0,1)$ such that

$$
2-\frac{2}{\pi} \arctan \left(\frac{1}{[d(T x, T y)]^{\alpha}}\right) \leq\left[2-\frac{2}{\pi} \arctan \left(\frac{1}{[d(x, y)]^{\alpha}}\right)\right]^{k}, \quad \text { for all } x, y \in X, T x \neq T y \text {. }
$$

Then $T$ has a unique fixed point.

\section{Competing interests}

The authors declare that they have no competing interests.

\section{Authors' contributions}

All authors contributed equally and significantly in writing this paper. All authors read and approved the final version.

\section{Acknowledgements}

This project was supported by King Saud University, Deanship of Scientific Research, College of Science Research Center.

Received: 2 August 2013 Accepted: 26 December 2013 Published: \#PUBLICATION_DATE

\section{References}

1. Banach, S: Sur les opérations dans les ensembles abstraits et leur applications aux équations intégrales. Fundam. Math. 3, 133-181 (1922)

2. Boyd, DW, Wong, JSW: On nonlinear contractions. Proc. Am. Math. Soc. 20, 458-464 (1969)

3. Ćirić, L: A generalization of Banach's contraction principle. Proc. Am. Math. Soc. 45(2), 267-273 (1974)

4. Kirk, WA: Fixed points of asymptotic contractions. J. Math. Anal. Appl. 277, 645-650 (2003)

5. Meir, A, Keeler, E: A theorem on contraction mappings. J. Math. Anal. Appl. 28, 326-329 (1969)

6. Rakotch, E: A note on contractive mappings. Proc. Am. Math. Soc. 13, 459-465 (1962) 
7. Reich, S: Fixed points of contractive functions. Boll. Unione Mat. Ital. 5, 26-42 (1972)

8. Suzuki, T: Fixed point theorem for asymptotic contractions of Meir-Keeler type in complete metric spaces. Nonlinear Anal. 64, 971-978 (2006)

9. Wardowski, D: Fixed points of a new type of contractive mappings in complete metric spaces. Fixed Point Theory Appl. 2012, 94 (2012)

10. Bari, CD, Vetro, P: Common fixed points in generalized metric spaces. Appl. Math. Comput. 218(13), $7322-7325$ (2012)

11. Branciari, A: A fixed point theorem of Banach-Caccioppoli type on a class of generalized metric spaces. Publ. Math. (Debr.) 57, 31-37 (2000)

12. Cherichi, M, Samet, B: Fixed point theorems on ordered gauge spaces with applications to nonlinear integral equations. Fixed Point Theory Appl. 2012, 13 (2012)

13. Das, P: A fixed point theorem on a class of generalized metric spaces. Korean J. Math. Sci. 9, 29-33 (2002)

14. Frigon, M: Fixed point results for generalized contractions in gauge spaces and applications. Proc. Am. Math. Soc. $128,2957-2965(2000)$

15. Janković, S, Kadelburg, Z, Radenović, S: On cone metric spaces: a survey. Nonlinear Anal. 74, 2591-2601 (2011)

16. Khamsi, MA, Kozlowski, WM, Reich, S: Fixed point theory in modular function spaces. Nonlinear Anal. 14(11), 935-953 (1990)

17. Kirk, WA, Shahzad, N: Generalized metrics and Caristi's theorem. Fixed Point Theory Appl. 2013, 129 (2013)

18. Lakzian, $\mathrm{H}$, Samet, B: Fixed points for $(\psi, \varphi)$-weakly contractive mappings in generalized metric spaces. Appl. Math. Lett. 25(5), 902-906 (2012)

19. Samet, B: Discussion on 'A fixed point theorem of Banach-Caccioppoli type on a class of generalized metric spaces' by A. Branciari. Publ. Math. (Debr.) 76(4), 493-494 (2010)

20. Sarama, IR, Rao, JM, Rao, SS: Contractions over generalized metric spaces. J. Nonlinear Sci. Appl. 2(3), 180-182 (2009)

21. Tarafdar, E: An approach to fixed point theorems on uniform spaces. Trans. Am. Math. Soc. 191, $209-225$ (1974)

22. Turinici, M: Functional contractions in local Branciari metric spaces (2012). arXiv:1208.4610v1 [math.GN]

23. Vetro, C: On Branciari's theorem for weakly compatible mappings. Appl. Math. Lett. 23(6), 700-705 (2010)

24. Nadler, SB Jr.: Multi-valued contraction mappings. Pac. J. Math. 30, 475-488 (1969)

25. Berinde, M, Berinde, V: On a general class of multi-valued weakly Picard mappings. J. Math. Anal. Appl. 326, 772-782 (2007)

26. Ćirić, L: Multi-valued nonlinear contraction mappings. Nonlinear Anal. 71, 2716-2723 (2009)

27. Markin, JT: A fixed point theorem for set-valued mappings. Bull. Am. Math. Soc. 74, 639-640 (1968)

28. Mizoguchi, N, Takahashi, W: Fixed point theorems for multivalued mappings on complete metric spaces. J. Math. Anal. Appl. 141, 177-188 (1989)

29. Naidu, SVR: Fixed point theorems for a broad class of multimaps. Nonlinear Anal. 52, 961-969 (2003)

30. Zhang, CK, Zhu, J, Zhao, PH: An extension of multi-valued contraction mappings and fixed points. Proc. Am. Math Soc. 128, 2439-2444 (2000)

31. Jleli, M, Samet, B: The Kannan's fixed point theorem in a cone rectangular metric space. J. Nonlinear Sci. Appl. 2(3), 161-167 (2009)

\#DIGITAL OBJECT IDENTIFIER

Cite this article as: Jleli and Samet: A new generalization of the Banach contraction principle. Journal of Inequalities and Applications \#CITATION

\section{Submit your manuscript to a SpringerOpen ${ }^{\circ}$ journal and benefit from:}

- Convenient online submission

- Rigorous peer review

Immediate publication on acceptance

Open access: articles freely available online

- High visibility within the field

- Retaining the copyright to your article 